\title{
Solução de Desafios por meio de um Modelo Baseado no Design Thinking e na Investigação Apreciativa
}

\section{Solution of Challenges Through a Model Based on Design Thinking and Appreciative Inquiry}

Gláucia de Salles Ferro ${ }^{1}$ Adriano Heemann ${ }^{2}$ 


\section{Resumo}

Gestores ligados à franquia enfrentam desafios de diversas naturezas em sua rotina profissional. Tais desafios, ligados ao universo da macroergonomia, demandam soluções rápidas e criativas. Por outro lado, equipes de designers enfrentam desafios semelhantes. O objetivo deste estudo é comparar os resultados da aplicação de um modelo para a solução de desafios, idealizado por meio do Design Thinking e da Investigação Apreciativa. Assim, foi realizada uma pesquisa -ação com workshops e ferramentas de Design. Os resultados sugerem que o modelo pode ser aplicado satisfatoriamente em diferentes contextos por meio de uma nova abordagem para o bem estar e a produtividade no ambiente de trabalho.

Palavras-chave: Design Thinking;, Colaboração; Macroergonomia; Franquia; Investigação Apreciativa.

\section{Abstract}

Managers linked to the franchise face challenges of various natures in their professional routine. These challenges, linked to the macroergonomics universe, require quick and creative solutions. On the other hand, design teams face similar challenges. The objective of this study is to compare the results of the application of a model for the solution of challenges, idealized through Design Thinking and Appreciative Inquiry. Thus, an action research was carried out with workshops and design tools. The results suggest that the model can be applied satisfactorily in different contexts through a new approach to well-being and productivity in the work environment.

Key-words: Design Thinking; Collaboration; Macroergonomic; Franchising; Appreciative Inquiry.

ISSN: 2316-7963

${ }^{1}$ Mestre em Design, UFPR (glaucia@frontesul.com.br)

${ }^{2}$ Doutor em Engenharia, UFPR (adriano.heemann@gmail.com) 


\section{INTRODUÇÃO}

O Design é uma atividade criativa cujo objetivo é estabelecer as qualidades multifacetadas de objetos, processos, serviços e seus sistemas em ciclos de vida completos (MOZOTA; KLÖPSCH; COSTA, 2010). Assim, o Design tem sido percebido como estratégico e vem sendo aplicado em diversas conjunturas (MOZOTA; KLÖPSCH; COSTA, 2010; BEST, 2012). Desta forma, os gestores de Design passam a participar da gerência da identidade gráfica, arquitetônica e também da construção de uma identidade coletiva organizacional (MARTINS; MERINO, 2008). A partir de tais atividades, esses profissionais aprendem a transitar entre diferentes fronteiras organizacionais, facilitando e viabilizando a comunicação e a colaboração entre os indivíduos (BEST, 2012). Neste sentido, os fatores humanos envolvendo as relações profissionais para o trabalho multidisciplinar surge como fator preponderante para o alcance dos objetivos empresariais. Tendo em vista a percepção do Design no âmbito estratégico organizacional e a urgência de se encontrar um modelo que leve em conta o fator humano como propulsor de um processo para a construção de projetos inovadores, surge o conceito de Design Thinking (DT). O DT almeja a inovação centrada no fator humano e se fundamenta na capacidade humana natural de ser intuitivo, de reconhecer padrões e desenvolver ideias significativas e funcionais para a promoção da inovação (BROWN, 2010; KELLEY; KELLEY, 2014). Por outro lado, o DT pode ser analisado também como um método e para tanto é aplicado em três fases: Inspiração, Idealização e Experimentação sempre por meio da colaboração (BROWN, 2010).

Este artigo propõe um Modelo de Análise e Solução de Desafios (MASD) que é composto pelos princípios do DT e também pelos fundamentos do método da Investigação Apreciativa (IA) que considera os aspectos positivos de cada ser humano para a construção de soluções criativas e de cenários otimistas para o universo organizacional.

A IA foi criada por Cooperrider e equipe em 1987 e é considerada uma derivação do método da Pesquisa-Ação (COOPERRIDER; SRIVASTRA, 1987). A IA proporciona um diálogo aberto e a intervenção social de modo mais propício à exploração de ideias do que a pesquisa-ação (VAN DER HAAR; HOSKING, 2004). O processo é formado pelo ciclo D da IA descrito pelas fases: Descoberta, Sonho, Planejamento e Futuro (COOPERRIDER; WHITNEY; STAVROS, 2009) e é aplicado por meio da colaboração multidisciplinar.

A análise e a proposição do modelo MASD abarcando os conceitos do DT e da IA foram escolhidos por seus aspectos similares e complementares. Tais aspectos partem do princípio de que a natureza humana, quando estimulada pode encontrar soluções criativas aplicáveis a diferentes contextos inclusive no âmbito da ergonomia organizacional ou macroergonomia.

A aplicação do modelo MASD proposto neste artigo se deu em dois contextos. O primeiro em um universo organizacional de uma rede de franquias e o segundo em um grupo de pesquisadores da área do Design.

A escolha da aplicação do modelo MASD junto a um grupo de stakeholders do universo de franquias deve-se à observação de uma demanda por ferramentas que auxiliem gestores a solucionar desafios de forma mais focada, criativa e eficaz (MAEMURA, 2009; RIBEIRO et al., 2011; FERRO, 2014; FERRO; HEEMANN, 2014). Por ou- 
tro lado, a escolha de um grupo de pesquisadores de Design teve por objetivo testar o modelo num contexto diferente do primeiro. O modelo e a demonstração de sua aplicação são apresentados neste artigo.

Os resultados advindos dos experimentos indicam a possibilidade do modelo ser utilizado para o aprimoramento das soluções relativas aos desafios organizacionais envolvendo os fatores humanos por meio das variáveis ambientais, tecnológicas e interpessoais previstas na macroergonomia.

\section{FUNDAMENTAÇÃO TEÓRICA}

A fundamentação teórica é oriunda de uma Revisão Bibliográfica Sistemática (RBS) inicialmente realizada conforme os apontamentos de Kitchenham (2004) e Higgins e Green (2011) sobre os seguintes temas: Design Thinking, Investigação Apreciativa, Colaboração e Macroergonomia e Franquia.

\subsection{Design Thinking}

Este artigo propõe o uso do Design em seu aspecto mais estratégico, que pretende servir como base para a proposta do Modelo. Assim, optou-se por utilizar inicialmente os princípios e os processos do DT.

Corroborando Mozota, Klöpsch e Costa (2010), o campo do Design tem afinidade com a gestão porque é uma atividade de resolução de problemas que segue um processo sistemático lógico e ordenado. Aprofundando a percepção do Design no campo da gestão, Ambrose e Harrys (2011) salientam que o Design é um processo que atende tanto a objetivos econômicos quanto criativos. O processo pode envolver equipes multidisciplinares para a resolução de um problema num projeto de Design ou de gestão empresarial. O elemento técnico e catalisador para o encontro da solução do problema é a prática do DT orientada aos negócios (AMBROSE; HARRYS, 2011).

Por outro lado, enquanto o Design traz em seu histórico embasamentos conceituais e teóricos advindos dos contextos da arte, da arquitetura, das engenharias e também do marketing, o DT é uma nova expressão para determinar a percepção sobre um determinado universo que leva em consideração o processo de pensamento utilizado pelo designer (BROWN, 2010; VIANNA et al., 2012). O DT destina-se a ajudar os participantes de um projeto por meio de um processo colaborativo a ver padrões e qualidades de problemas ao invés de alternativas predefinidas (HATCHUEL, 2002; BOLAND JR.; COLLOPY, 2004).

De acordo com Brown (2010), em algumas empresas de Design, a abordagem do DT orientada às pessoas levou a uma mudança significativa do Design de produtos de consumo para o Design de experiências de consumo. Essa enfatização da abordagem do DT voltada para as pessoas levou empresas a adotarem o DT no âmbito estratégico organizacional visando à inovação (MOZOTA; KLÖPSCH; COSTA, 2010). Assim, essa forma de promover a inovação torna-se a base da gestão empresarial no início do século XXI como propõe Martin (2010).

As empresas adeptas do DT destacam-se por sua disposição em assumir a tarefa 
de continuamente redesenhar seus negócios. Fazem isso com foco na criação de avanços tanto em termos de inovação quanto em termos de eficiência - combinação que produz uma significante vantagem competitiva (MARTIN, 2010).

Para a prática do Design inovador e do alcance do pensamento estratégico empresarial, Brown (2010) propõe um processo de um projeto de DT. Embora seja apresentado de forma linear, o processo é iterativo. A Figura 1 indica essa relação:

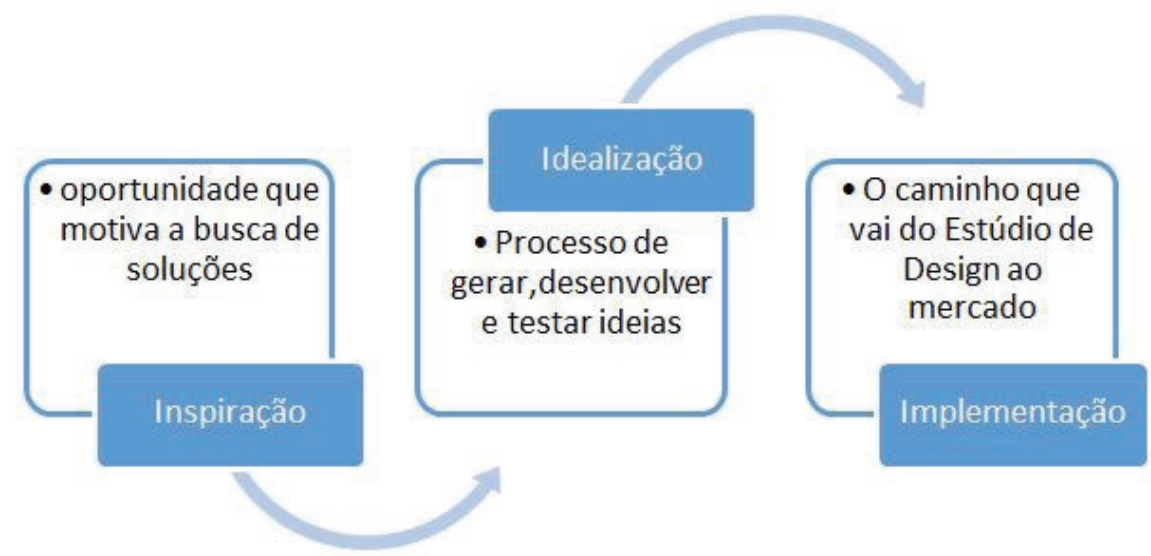

Figura 1: Processo de um Projeto de DT. Fonte: Brown (2010).

Como é possível notar, o processo de inovação no DT parte de um "problema" que deve ser solucionado, por isso Vianna et al. (2012, p. 14) afirmam que não se pode solucionar problemas com o mesmo tipo de pensamento que os criou: abduzir e desafiar as normas empresariais é a base do DT.

Outro processo para a promoção da inovação no âmbito do DT pode ser compreendido pelo modelo proposto por Martin (2010, p. 9), denominado "Funil do Conhecimento" (Figura 2) e que tem por objetivo mostrar como os processos, estruturas e habilidades podem ser captados para gerar algum insight inovador.

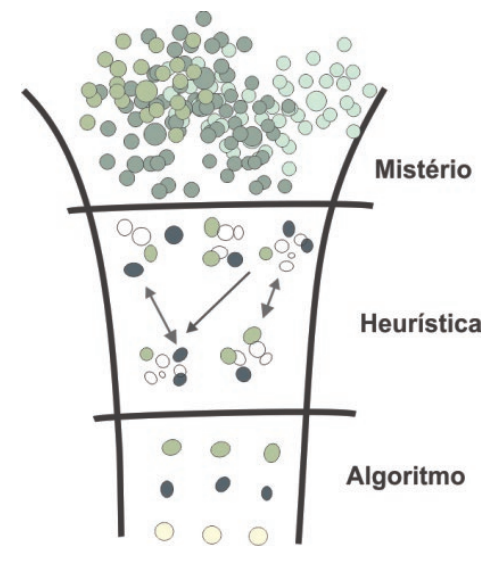

Figura 2: Funil do Conhecimento Fonte: Adaptado de Martin (2010, p. 9)

As considerações de Martin (2010, p. 41-42) para o Funil do Conhecimento refletem a postura empresarial a partir de tomadas de decisões relativas a cada fase do Funil do Conhecimento. As ponderações são apresentadas no Quadro 1: 
Quando a empresa aperfeiçoa suficientemente sua heurística e a avança no Funil do Conhecimento até o estágio do algoritmo, os custos caem e a eficiência aumenta, beneficiando a organização e seus stakeholders.

Uma organização que se define exclusivamente baseada em algoritmos está correndo riscos cataclísmicos que ocorrem quando o futuro não mais se assemelha ao passado e o algoritmo deixa de ser relevante.

O pensamento analítico adotado de forma objetiva e consistente numa corporação não leva à inovação, tampouco o pensamento puramente intuitivo. Uma possibilidade considerável é a prática do DT.

Quadro 1: Considerações sobre as Tomadas de Decisões Empresariais nas Fases do Funil do Conhecimento. Fonte: Adaptado de Martin (2010, p. 41-42).

Outro fator preponderante na prática do DT são os fatores humanos que, por meio do trabalho em equipe se desenvolve na rede das relações humanas no contexto estratégico empresarial. Assim, Brian (2012) propõe a seguinte reflexão:

Cada vez mais, as partes interessadas de todos os tipos - clientes, colaboradores, fornecedores e parceiros estratégicos - parecem dispostos e capazes de desempenhar um papel mais ativo no processo de criação de valor. Os gestores, por outro lado, necessitam aprender a usar as novas ferramentas de engajamento tais como: o pensamento design, valor, cocriação e o poder de estimular (BRIAN, 2012, p. 25).

Num processo de DT a colaboração, por meio de equipes multidisciplinares para a elucidação de um desafio, envolve as seguintes fases (Quadro 2):

\begin{tabular}{ll}
\hline 1. Entender & $\begin{array}{l}\text { Adquirir conhecimentos básicos sobre os usuários e da situação/ } \\
\text { problema geral }\end{array}$ \\
\hline 2. Observar & Ganho de empatia com os usuários por perto \\
\hline 3. Definir Ponto de Vista & $\begin{array}{l}\text { Criar um usuário típico para o qual a solução/produto está sendo } \\
\text { projetado }\end{array}$ \\
\hline 4. Idealizar & Gerar o maior número de ideias possível \\
\hline 5. Fazer um Protótipo & Construir protótipos reais \\
\hline 6. Testar & Aprender com as reações dos usuários aos diversos protótipos \\
\hline
\end{tabular}

Tendo em vista as ponderações descritas por dois pesquisadores do DT foi possível estabelecer um painel apresentado no Quadro 3, no qual ficam evidentes os elementos fundamentais que pautam esta estratégica prática de Design: 


\begin{tabular}{|c|c|c|c|c|c|}
\hline $\begin{array}{c}\text { Funil do } \\
\text { Conhecimento }\end{array}$ & \multicolumn{4}{|c|}{ Fases do Processo e suas interações } & \multirow{4}{*}{$\begin{array}{l}\text { Neutro } \\
\text { Iterativo } \\
\text { Ilimitado }\end{array}$} \\
\hline Processo & 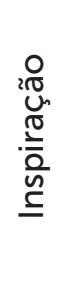 & 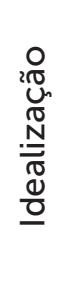 & 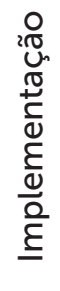 & 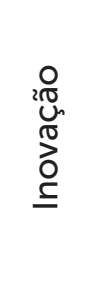 & \\
\hline Equipe & $\begin{array}{l}\frac{0}{0} \\
\frac{0}{0} \\
0 \\
0\end{array}$ & $\begin{array}{l}\frac{0}{0} \\
\frac{1}{d} \\
\frac{d}{\nu} \\
\frac{\text { 을 }}{\varepsilon}\end{array}$ & 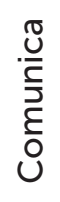 & $\begin{array}{l}\frac{\pi}{0} \\
\frac{0}{\pi} \\
\frac{0}{0}\end{array}$ & \\
\hline Meios & $\frac{\frac{1}{0}}{\frac{\pi}{>}}$ & 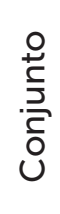 & $\begin{array}{l}\frac{0}{0} \\
\frac{\pi}{0} \\
\frac{0}{2} \\
\frac{0}{0} \\
\frac{0}{2}\end{array}$ & 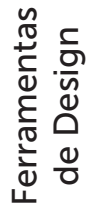 & \\
\hline
\end{tabular}
(2010), Steinbeck (2011), Stempfle e Badke-Schaub (2002), Johansson-Sköldberg, Woodilla e Çetinkaya (2013).

\subsection{Investigação Apreciativa}

A IA foi desenvolvida por David Cooperrider, Ronald Fry, Suresh Srivastva e seus colaboradores, na Case Western Reserve University, EUA, em 1987 (COOPERRIDER; WHITNEY; STAVROS, 2009). A construção da expressão IA se dá pelas palavras "Investigar" (o ato da exploração e descoberta) e "Apreciar" (o ato de reconhecer o melhor nas pessoas e no mundo), de tal modo que indicam para o que se pode vislumbrar em termos de resultados de pesquisas (COOPERRIDER; WHITNEY; STAVROS, 2009, p. 380-381). A partir dessa premissa o Quadro 4 apresenta a categorização dos princípios do método da IA. Tais princípios se organizam a partir das posturas do ser humano no ambiente de trabalho.

\begin{tabular}{cl}
\hline Princípio & \multicolumn{1}{c}{ Conceito } \\
\hline \multirow{2}{*}{ Construcionista } & $\begin{array}{l}\text { As organizações são percebidas como construções humanas. } \\
\text { O conhecimento individual e o destino das organizações estão } \\
\text { interligados. }\end{array}$ \\
\hline Simultaneidade & $\begin{array}{l}\text { A pergunta e a mudança acontecem simultaneamente. A pergunta } \\
\text { apreciativa favorece a autoestima de outra pessoa. }\end{array}$ \\
\hline \multirow{3}{*}{ O poder da Pergunta } & A IA enfoca na força de uma pergunta como estimuladora \\
& $\begin{array}{l}\text { de respostas que constroem o futuro. Perguntas que geram } \\
\text { negativismo, desconfiança e medo podem ser substituídas por } \\
\text { outras que geram ações positivas. }\end{array}$ \\
\hline Poético & $\begin{array}{l}\text { As organizações humanas podem ser vistas como livros abertos } \\
\text { em que as pessoas são coautoras. As metáforas usadas para } \\
\text { comunicação daquilo que é a organização impulsionam a criação } \\
\text { e a mudança para o novo. }\end{array}$ \\
\hline
\end{tabular}




\begin{tabular}{cl}
\hline Afirmativo/Positivo & $\begin{array}{l}\text { Perguntas que solicitam respostas positivas criam imagens } \\
\text { positivas, que levam a ações positivas que criam imagens positivas. }\end{array}$ \\
\hline \multirow{2}{*}{ Princípio Imaginário } & $\begin{array}{l}\text { O ato de compartilhar imagens do futuro ou histórias inspiradoras } \\
\text { do passado, numa criação coletiva, pode provocar uma visão de } \\
\text { êxito. }\end{array}$ \\
\hline
\end{tabular}

Aprofundando a compreensão do método, a pesquisa apreciativa deriva-se de outro método denominado pesquisa-ação, porém há diferenças entre eles. No Quadro 5, são apresentadas tais diferenças e também suas complementaridades.

\begin{tabular}{|c|c|c|c|}
\hline \multicolumn{2}{|c|}{ Oposições } & \multicolumn{2}{|c|}{ Complementaridades } \\
\hline $\begin{array}{l}\text { Investigação } \\
\text { Apreciativa }\end{array}$ & Pesquisa-Ação & $\begin{array}{c}\text { Investigação } \\
\text { Apreciativa }\end{array}$ & Pesquisa-Ação \\
\hline $\begin{array}{l}\text { Dedica-se às práticas } \\
\text { sociais e organizacio- } \\
\text { nais }\end{array}$ & $\begin{array}{l}\text { Interesse investigativo } \\
\text { voltado para a prática } \\
\text { social }\end{array}$ & $\begin{array}{l}\text { Orientada pelo Socior- } \\
\text { racionalismo. }\end{array}$ & $\begin{array}{l}\text { Orientada pelo para- } \\
\text { digma Socioconstru- } \\
\text { cionista }\end{array}$ \\
\hline $\begin{array}{l}\text { Esforços coletivos para } \\
\text { a mudança transfor- } \\
\text { macional }\end{array}$ & $\begin{array}{l}\text { Interação social para } \\
\text { prover processos de } \\
\text { mudança e transfor- } \\
\text { mação social }\end{array}$ & $\begin{array}{l}\text { Foco em premissas } \\
\text { positivas. }\end{array}$ & $\begin{array}{l}\text { Foco na resolubilidade } \\
\text { de problemas }\end{array}$ \\
\hline $\begin{array}{l}\text { Interação dialógica e } \\
\text { participativa entre os } \\
\text { agentes do processo }\end{array}$ & $\begin{array}{l}\text { Intervenção social e } \\
\text { participativa }\end{array}$ & Orienta-se por sonhos. & $\begin{array}{l}\text { Orienta-se por plane- } \\
\text { jamento }\end{array}$ \\
\hline \multirow[t]{2}{*}{$\begin{array}{l}\text { Direcionamento dialó- } \\
\text { gico, interativo, positi- } \\
\text { vo e transformativo }\end{array}$} & $\begin{array}{l}\text { Direcionamento par- } \\
\text { ticipativo, orientado } \\
\text { para a prática, visando } \\
\text { encontrar soluções } \\
\text { para os problemas } \\
\text { sociais e emancipar os } \\
\text { indivíduos e grupos. }\end{array}$ & $\begin{array}{l}\text { Origem/fontes: a teoria } \\
\text { crítica, a etnografia, } \\
\text { o estudo de caso, a } \\
\text { análise de narrativa e } \\
\text { a pesquisa ação, bem } \\
\text { como a epistemoló- } \\
\text { gico construcionista } \\
\text { social e o paradigma } \\
\text { sociorracionalista. }\end{array}$ & $\begin{array}{l}\text { Origem/fontes: a pe- } \\
\text { dagogia revolucionária } \\
\text { de Paulo Freire, a so- } \\
\text { ciologia da libertação } \\
\text { de Orlando Fals-Borda } \\
\text { e as críticas feministas } \\
\text { e as reconceitualiza- } \\
\text { ções da força sociocul- } \\
\text { tural. }\end{array}$ \\
\hline & & $\begin{array}{l}\text { Orienta-se metodolo- } \\
\text { gicamente pelo ciclo } \\
\text { dos quatro Ds. }\end{array}$ & $\begin{array}{l}\text { Orienta-se metodolo- } \\
\text { gicamente pelo ciclo } \\
\text { básico de investigação } \\
\text {-ação. }\end{array}$ \\
\hline
\end{tabular}

Quadro 5: Análise Comparativa entre o método da Investigação Apreciativa e da Pesquisa-Ação. Fonte: Silva, Costa Filho e Brito (2013).

Uma vez explicados os fundamentos do método da IA, inicia-se a reflexão sobre como se dá a aplicação da IA. O processo se desencadeia a partir do pressuposto de que toda organização possui algo que funciona bem e essas forças podem ser o ponto de partida para a criação de uma mudança positiva (COOPERRIDER; WHITNEY; STAVROS, 2009). Essa premissa fundamenta o pensamento estratégico da organização, onde os participantes descobrem novas informações sobre suas melhores experiências no passado, antes de formar uma imagem do futuro (FRY et al., 2002). Tal 
processo se aplica também a projetos independentes.

Corroborando a percepção do processo colaborativo inerente à IA, Varona (2009) destaca outro pressuposto. Ele afirma que o conhecimento e a visão da realidade no processo de IA são construídos de forma coletiva e por meio da linguagem porque a realidade se constrói durante as interações sociais.

Dando continuidade aos aspectos de aplicação prática, o método da IA segundo seus idealizadores (COOPERRIDER; WHITNEY; STAVROS, 2009), envolve, num primeiro estágio, todos os membros de uma organização com diálogos a respeito de forças, recursos e capacidades. Num segundo momento, mobiliza as pessoas por meio de atividades concentradas vitalizando os sonhos mais centrados no futuro. A partir daí são geradas as propostas que orientam o futuro conjunto, envolvendo equipes para realizar o trabalho necessário para concretizar as propostas. Esse processo é chamado de Ciclo 4D que é ilustrado na Figura 3:

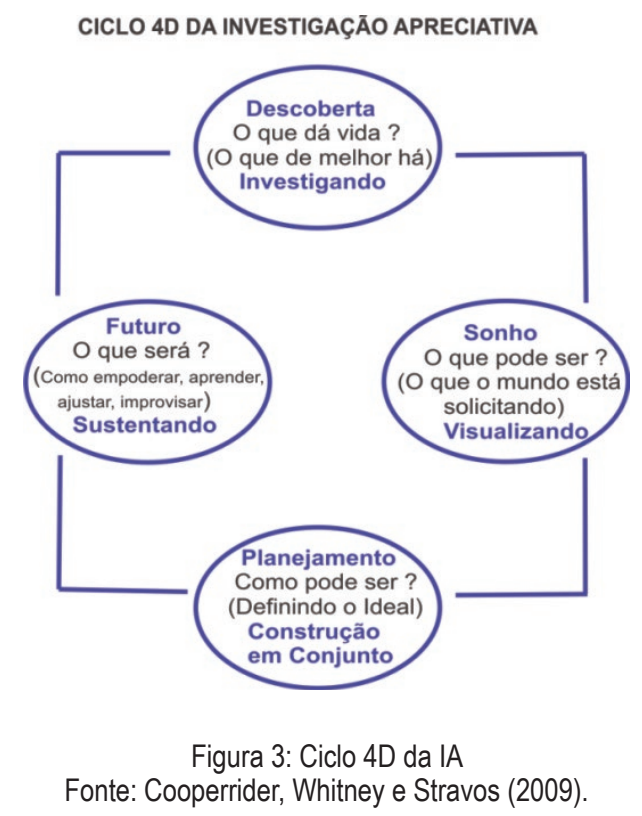

Tendo em vista os conceitos apresentados, Fry et al. (2002) e Cooperrider, Whitney e Stavros (2009) enfatizam que, partindo da implantação do método no universo escolhido, há que se almejar algum tipo de mudança positiva no clima organizacional de uma empresa ou na predisposição de colaboração em um grupo que desenvolve alguma atividade em conjunto com objetivos comuns.

Tendo em vista o uso do processo do Ciclo 4D, Cooperrider e Srivastva (2000) extrapolam ao traçar os paradigmas comparando as práticas tradicionais de percepção de solução de problemas com as práticas da IA.

\begin{tabular}{cc}
\hline Paradigma 1: Solução do Problema & Paradigma 2: IA \\
\hline $\begin{array}{c}\text { Necessidade percebida - Identificação do } \\
\text { Problema }\end{array}$ & $\begin{array}{c}\text { Apreciar e dar valor ao que há de melhor } \\
\text { "no que é" }\end{array}$ \\
\hline Análise das Causas & Vislumbrar "O que pode ser" \\
\hline Análise de Possíveis Soluções & Dialogar "O que deveria ser" Inovar "O que será" \\
\hline
\end{tabular}


Pressuposto Básico: Uma organização é um problema a ser resolvido
Pressuposto Básico: Uma organização é um mistério a ser abraçado

Quadro 6: Dois Paradigmas para a Mudança Organizacional. Fonte: Cooperrider e Srivastva (2000).

Por outro lado, os resultados que têm sido alcançados com a aplicação do método da IA no contexto organizacional, segundo Cooperrider, Whitney e Stravos (2009), são os seguintes: elevação da satisfação dos empregados; incremento da produtividade; aumento dos níveis de comunicação entre os interessados; redução da rotatividade; estímulo da criatividade e alinhamento da organização em torno da visão, missão, objetivos e estratégias.

Com tais resultados percebidos pelos idealizadores do método da IA é possível vislumbrar decorrências positivas voltadas a diversos tipos de demandas que envolvam a solução de um desafio ou o alcance de um objetivo.

\subsection{Macroergonomia e Colaboração}

O conceito de Ergonomia aqui abordado é anterior ao conceito da macroergonomia e está embasado historicamente nos fatores humanos e interdisciplinares que foram despertados a partir da segunda guerra mundial (IIDA, 2005).Neste sentido, algumas instituições que investigam o tema como a Associação Brasileira de Ergonomia (ABERGO, 2018) têm o entendimento de que ergonomia é uma disciplina científica relacionada às interações entre os seres humanos e outros sistemas, e à aplicação de teorias, princípios e métodos a projetos a fim de otimizar o bem estar humano e o desempenho global do sistema. Falzon (2007) afirma ainda que este campo de estudo pode ser compreendido a partir do aspecto holístico do homem, ou seja, em suas dimensões sociais, fisiológicas e cognitivas. A partir desta visão holística é possível inferir que o ser humano é capaz de produzir conhecimentos para realizar atividades, para a criação de soluções no ambiente de trabalho e também para a colaboração.

Se a ergonomia tem um campo de estudo delimitado e está voltada à compreensão do homem como um todo, a colaboração por outro lado, é objeto de estudo de várias áreas do conhecimento e pode ser considerada condição fundamental do desenvolvimento na sociedade contemporânea (LOTAZZ et al.,1999). Ela é o empenho de um indivíduo que contribui para a realização de algo conjunto ou para ajudar alguém (FERREIRA, 2004, p. 494).

Como é possível notar, existe uma relação entre os temas colaboração e ergonomia e por isso neste artigo são investigados concomitantemente.

Visando aprofundar o entendimento sobre a abrangência da ergonomia é necessário lembrar que sua origem está atrelada à indústria a partir da revolução industrial, mas sua evolução levou a investigações voltadas ao ambiente empresarial, e por isso, na década de 1980 surgiu a subdisciplina denominada "macroergonomia ou ergonomia organizacional" (IIDA, 2005; CORREAA e BOLETTI, 2015). Sampaio e Souza (2012) e Hendrick e Kleiner (2006) acrescentam que a ergonomia organizacional é baseada em um método participativo de gestão das organizações, no qual o ser 
humano envolvido no processo de trabalho contribui para que as intervenções necessárias tenham uma maior assertividade. Tais intervenções podem ocorrer a partir das variáveis ambientais, tecnológicas e interpessoais (MEDEIROS, 2005). A partir de tais noções é possível deduzir que no âmbito interpessoal o incentivo à colaboração pode contribuir de forma eficaz para os resultados almejados por uma organização. Corroborando com este entendimento Hendrick e Kleiner (2006) entendem que a macroergonomia não se configura a partir de procedimentos metodológicos delimitados, mas organiza-se a partir de sua aplicação, desenvolvimento e validação. Tendo em vista esta percepção, tais procedimentos poderiam ser criados com equipes multidisciplinares e colaborativas.

Com as premissas do campo de estudo da ergonomia e das especificidades da macroergonomia é possível enfocar os aspectos colaborativos aplicados ao design. Assim sendo, Para Chiu (2002), o Design colaborativo pode ser compreendido como uma atividade que requer a participação individual para o compartilhamento de informações e também para a organização de tarefas, recursos e responsabilidades. Deste modo, diversos componentes organizacionais precisam estar alinhados; entre eles, liderança, estrutura e estratégia (STRAUS, 2003, p. 27).

A partir dos conceitos complementares de Design colaborativo é possível fazer uma reflexão a respeito dos resultados desejados da prática colaborativa. Assim, Heemann, Lima e Corrêa (2008) entendem que a colaboração, o compartilhamento, a cooperação e o trabalho em equipe assumem papéis acessórios de um fim maior: uma profunda interação e fusão de valores que culminem na resolução conjunta de problemas.

A urgência na busca pela prática colaborativa, esteja ela envolvida em projetos de Design ou multidisciplinares, fez com que se buscasse algum modelo a ser adotado visando ao alcance de algum resultado mais efetivo. O modelo mais difundido e adotado por pesquisadores é o Modelo $3 \mathrm{C}$ de colaboração idealizado por Ellis, Gibbs e Rein (1991), que é entendido como a ação de realizar o trabalho em conjunto, envolvendo a comunicação, "comum-ação", ação de tornar comum negociação e compromissos; a cooperação, "co-operar-ação", ação de operar em conjunto; a coordenação, "co-ordem-ação", ação de ordenar em conjunto: pessoas, tarefas e recursos.

\begin{tabular}{cc}
\hline Comunicação & Troca de mensagens, argumentação e negociação \\
\hline Coordenação & Gerenciamento de pessoas, atividades e recursos \\
\hline Cooperação & Atuação conjunta no espaço compartilhado para a produção de \\
objetos e informações
\end{tabular}

De acordo com o Quadro 7 a comunicação, sendo um processo, geralmente envolve a participação de pessoas com diferenças culturais; por isso, Ellis, Gibbs e Rein (1991) afirmam ser necessário haver um conhecimento compartilhado, de modo que o significado da comunicação seja compreendido e crie-se desta forma o senso comum.

Sobre o tema comunicação, se faz necessária a presença de um líder que coordene as atividades divididas em pequenas partes ou simples tarefas (PIMENTEL; FUCKS, 2012). 
Em termos de cooperação, a reflexão indica que o objetivo de um trabalho em grupo, em geral, é produzir algo; pode ser um produto ou uma solução. Assim, é preciso um espaço de compartilhamento, para que todos possam trabalhar juntos (cooperar).

A principal diferença entre coordenação e cooperação, segundo Boujut e Laureillard (2002), reside na intenção dos diferentes participantes: cooperação requer um conjunto comum de metas e que não pode ser dada a priori. Esta diferença justifica a necessidade de diferenciar claramente um projeto em cooperação e a coordenação no projeto de Design.

O tema colaboração no universo do projeto de Design de produto levaram os pesquisadores a perceber que o contato entre o designer e as pessoas envolvidas no projeto aumentam as chances de o projeto ser bem-sucedido (SCARIOT; HEEMANN; PADOVANI, 2012). O Quadro 8 apresenta esses tipos de envolvimento:

\begin{tabular}{ccc}
\hline Tipo de Envolvimento & Descrição \\
\hline Informativo & $\begin{array}{c}\text { O utilizador é visto como uma fonte de informação. O designer } \\
\text { coleta as informações consideradas necessárias para o } \\
\text { desenvolvimentodo projeto. }\end{array}$ \\
\hline Consultivo & $\begin{array}{c}\text { O designer propõe soluções e as traz para os usuáriospara que } \\
\text { eles possam avaliar e formar opiniões sobre tais soluções. }\end{array}$ \\
\hline Participativo & A organização é transferida para os usuários e, assim, eles se \\
percebem com algum poder sobre o projeto.
\end{tabular}

Quadro 8: Possibilidades de Envolvimento dos Usuários e Designers num Projeto Colaborativo. Fonte: Adaptado de Scariot, Heemann e Padovani (2012).

Os conceitos até aqui apresentados são aplicáveis a diversos contextos e essa aplicação dependerá da forma como será conduzida (coordenação) para que o resultado do processo colaborativo seja satisfatório.

\subsection{Franquia}

As pesquisas acadêmicas sobre o termo franquia vêm sendo estudadas no Brasil e no mundo com diferentes enfoques. No Brasil e no âmbito internacional as pesquisas são direcionadas aos temas empreendedorismo, estratégia, internacionalização, contratos e conflitos (MELO; ANDREASSI, 2012). Pouca importância tem sido dada ao tema Design e suas aplicações (OMITIDO PARA REVISÃO CEGA, 2013). O modelo de negócios denominado franquia empresarial tem por princípio o repasse de know-how, a disponibilização de produtos e/ou serviços diferenciados e a cessão de uso de marca a empreendedores que desejam abrir empresas seguindo o padrão da empresa original (CHERTO et al., 2006). O processo que envolve o repasse desse know-how exige aperfeiçoamento constante e acolhe contribuições de várias áreas do conhecimento, tais como: Design, colaboração, marketing, empreendedorismo, gestão, psicologia, entre outras (MAURO, 2006). Assim sendo, o sistema de franquias é apresentado por Ribeiro et al. (2011) da seguinte forma:

É uma estratégia de expansão dos negócios que envolve a transferência de know-how e métodos de se fazer as coisas entre duas par- 
tes, a Franqueadora e o Franqueado, que constroem uma relação de longo prazo visando resultados sustentáveis e duradouros, além de se desenvolverem constantemente na busca de maior participação de mercado, de forma rentável e dentro de modelos de negócios em que o planejamento e a gestão estratégica são fundamentais para a consecução dos resultados esperados (RIBEIRO et al., 2011, p. 22).

Esse universo organizacional apresenta uma complexidade relativa a diversos aspectos, mas especialmente no que se refere à manutenção do padrão de qualidade da prestação de serviços. Esse padrão de qualidade envolve processos e pessoas e as transformações inerentes a ambos. Conforme Ribeiro et al. (2011), os principais representantes nessa relação de prestação de serviços são:

a) a Franqueadora - uma empresa que concede a franquia, sendo considerada a detentora dos direitos sobre a marca, método e processos do negócio e que seleciona os seus franqueados para poder representá-la por meio de franquia;

b) o Franqueado - aquele que compra a franquia; é o proprietário de uma unidade da rede franqueada, podendo ser pessoa física ou pessoa jurídica;

c) os Fornecedores - empresas que fornecem produtos e/ou serviços à franqueadora e aos franqueados.

A qualidade da prestação de serviços ao cliente final está estreitamente ligada à perpetuação do sucesso da rede de franquias ao longo dos anos (PLÁ, 2001). Desta forma, tanto a franqueadora quanto os franqueados têm os mesmos interesses em ver o negócio bem-sucedido. No entanto, há descordos relativos à percepção de "como" se dá esse sucesso (PLÁ, 2001; TAKAHASHI, 2003). Por isso, é possível ocorrer conflitos entre os stakeholders (MAEMURA, 2009). Nathan (2000) reforça a percepção de que, se forem enfocados somente contratos, finanças e mercados e ignorada a dimensão humana do franchising - os sentimentos, motivações e comportamentos das pessoas -, será ignorado o próprio núcleo da franquia.

Outra dimensão que abarca a gestão eficaz do sistema de franquias diz respeito aos processos que envolvem a formatação de uma franquia, ou seja, o modelo inicial do negócio (RIBEIRO et al., 2011). A estruturação da empresa em torno de seus processos de negócio significa uma mudança na postura administrativa tradicional, cujo enfoque estava no gerenciamento de como as atividades eram executadas individualmente, para uma visão global e dinâmica de toda a empresa (THIVES JR., 2001). No caso da franquia, a visão global e dinâmica envolve algo equivalente a diferentes unidades de negócios de uma mesma empresa.

O aspecto comunicação também deve ser considerado como um ingrediente crucial nas relações sociais e que representa uma base para a obtenção do compromisso (MOOHR; SPEKMAN, 1994). No caso das franquias, faz-se necessário explorar a comunicação colaborativa, a partir da qual os franqueadores podem comunicar-se com os franqueados e influenciá-los de modo frequente, formal, racional e recíproco (JOSHI, 2009), conseguindo assim ampliar sua credibilidade além da demonstração de comprometimento com toda a rede. 


\section{MÉTODO}

O método escolhido para o desenvolvimento do experimento intitulado Modelo de Análise para Solução de Desafios (MASD) integra as abordagens do DT e da IA aplicadas em dois contextos diferentes. Assim, apresenta-se o detalhamento da pesquisa.

As unidades de análise foram assim delimitadas:

1. Uma rede de franquias representada num primeiro momento por gestores da franqueadora (empresa de serviços responsável pela marca e know-how do negócio) e num segundo momento, por profissionais da franqueadora e de uma unidade de franquia (empresa que replica o know-how do negócio). É importante ressaltar que o ambiente macroergonômico da franqueadora é distinto do ambiente macroergonômico da unidade de franquia;

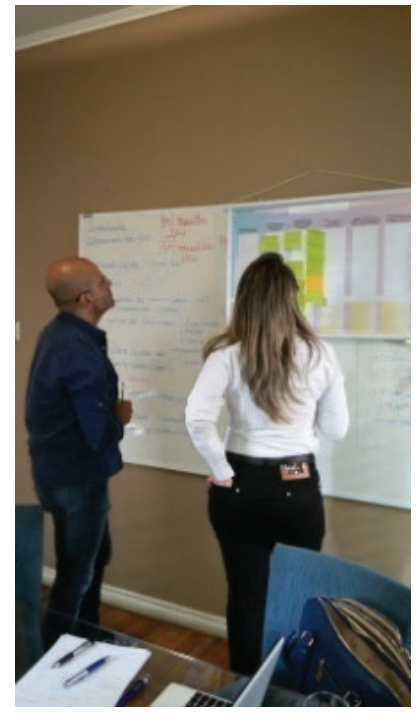

Figura 4: Gestores da franqueadora buscando a solução do desafio por meio do workshop colaborativo. Fonte: Os autores.

A escolha dos profissionais da rede de franquias se deu devido à necessidade que esse tipo de negócio apresenta de manter um clima organizacional positivo e, ao mesmo tempo, de resolver desafios cotidianos de modo colaborativo.

2. Um grupo de pesquisadores das áreas do Design e da engenharia participantes de uma conferência internacional de inovação.

A escolha dos pesquisadores ocorreu devido à oportunidade de se testar o modelo MASD junto a um público mais esclarecido sobre os conceitos envolvidos, visando à identificação de falhas e de possiveis aperfeiçoamentos.

Os participantes inscreveram-se voluntariamente para participar do workshop que testava o modelo MASD. Nesse caso, não se objetivou alcançar todos os participantes do evento, mas só os que se interessaram pelo tema proposto que foi a inovação. Neste caso a aplicação de seu no ambiente macroergonômico do evento. Tendo em vista a escolha dos contextos ( 1 e 2), a estratégia de pesquisa se deu com a criação de um modelo híbrido envolvendo o processo do DT e do método da IA e a concomitante análise do contexto envolvendo os conceitos da macroergonomia. A fusão das etapas do ciclo do DT e da IA determinou o modelo MASD.

$O$ processo do DT foi escolhido por ser um modelo mental baseado num pen- 
samento sistêmico de aprendizado, que ajuda a inovar de modo empírico e, de certa forma, lúdico. Já o ciclo da IA foi utilizado por envolver pressupostos como apreciar, vislumbrar e dialogar (Quadro 6) que enriquecem a vivência dos participantes durante o workshop no qual se baseia a aplicação do modelo MASD. Ao mesmo tempo, se constrói uma nova percepção do ambiente produtivo e colaborativo dando ao participante a oportunidade de se integrar a um projeto ou tarefa de modo gratificante.

O propósito de integrar os elementos do DT e o método da IA foi o de extrair de ambos apenas os elementos que, embora parecidos, possam se tornar ferramentas para diagnosticar um cenário de desafio empresarial ou de projeto e, a partir daí propor soluções. O processo que envolve o modelo dura entre 1 e 2 horas e pode ser aplicável a vários tipos de desafios. Além disso, o modelo pode ser reaplicado sempre que se fizer necessário, inclusive para se encontrar respostas diferentes para o mesmo desafio. A Figura 5 ilustra o modelo MASD e as fases do workshop de aplicação.

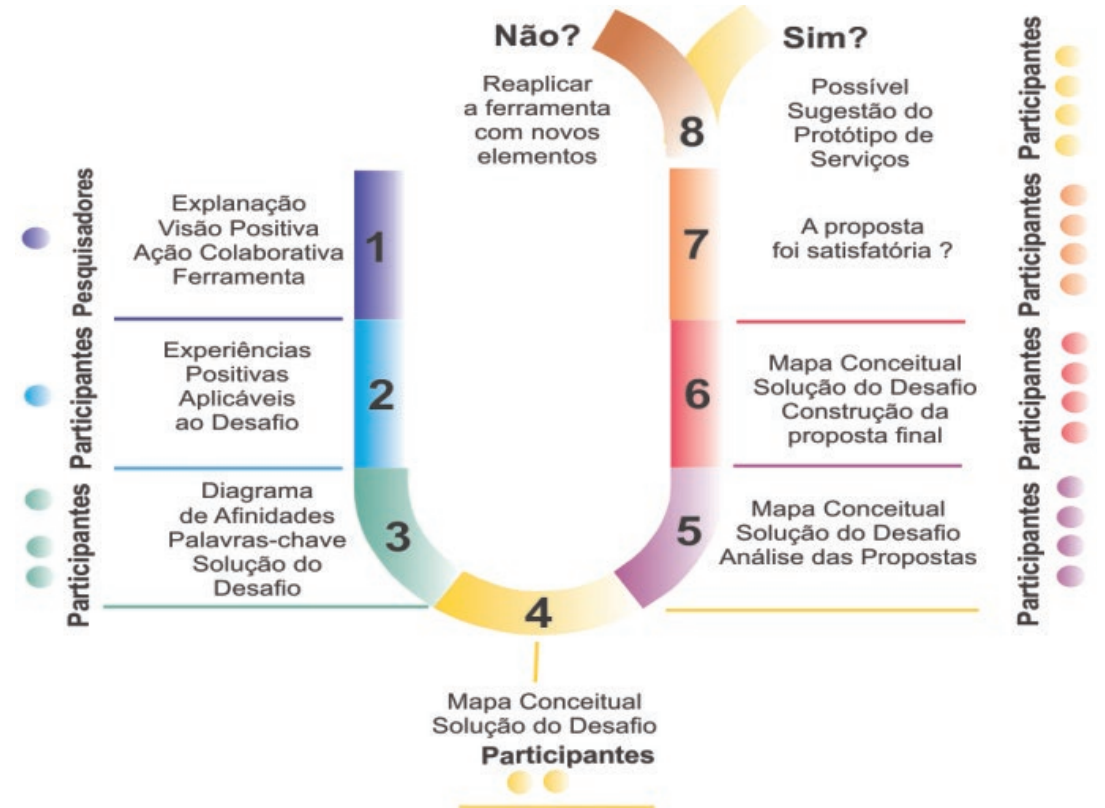

Figura 5: Modelo de Solução de Desafios Fonte: Os autores.

A aplicação do método a partir do modelo MASD se dá por meio de duplas ou grupos colaborativos, de preferência multidisciplinares. Assim sendo, cada fase do modelo é apresentada da seguinte forma:

- A fase 1 inicia o workshop a partir da criação de um clima positivo. Esse clima positivo se conquista com a leitura de um texto que propõe uma reflexão positiva, com uma música ou, ainda, apresentando-se um vídeo inspirador;

- A fase 2 envolve a proposição do desafio com foco bem definido (que foi previamente determinado pelos participantes) e a sugestão para que os participantes busquem na memória referências positivas para desafios semelhantes que resultaram de modo satisfatório. Por exemplo: se o desafio era relativo a como se comunicar melhor com alguém, o participante poderia lembrar-se de uma vivência da infância na qual ele conseguiu se comunicar melhor com alguém por meio da intervenção de um amigo. Isso poderia provocar um insight para que, no contexto daquele desafio, ele pudesse contar com a ajuda de outro colega; 
- Na fase 3 os envolvidos escrevem em pequenos papéis adesivados a síntese dos insights que tiveram na fase anterior e colam esses papéis num painel denominado diagrama de afinidades. Na sequência, cada participante apresenta ao grupo as sínteses das suas ideias e, de modo colaborativo, cada grupo discute e avalia os insights;

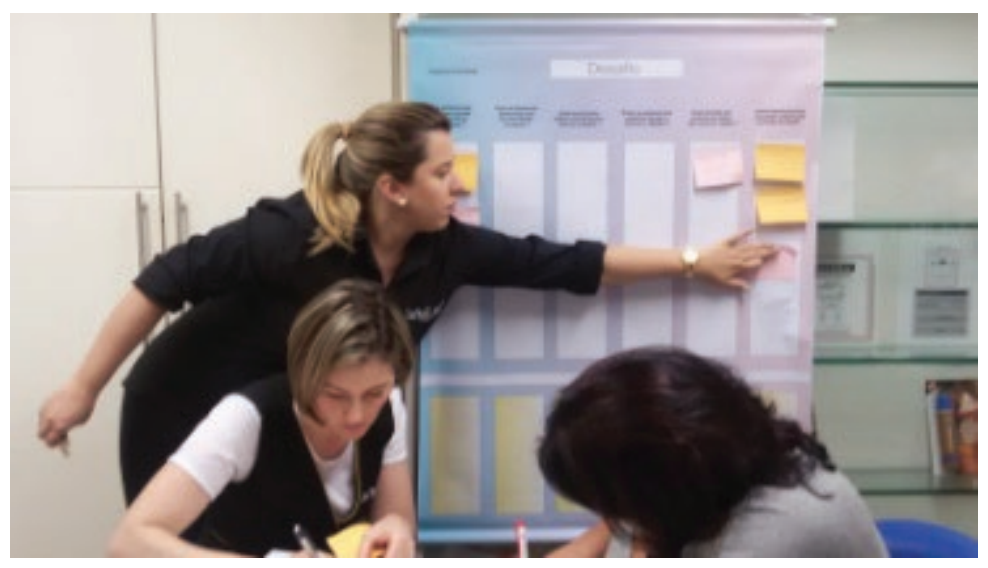

Figura 6: Construção do diagrama de afinidades. Fonte: Os autores.

- Na fase 4 os participantes de cada grupo escolhem os melhores insights e a partir deles desenham um mapa conceitual, ou seja, uma espécie de fluxograma que demonstra como o desafio pode ser resolvido em suas diferentes etapas;

- Na fase 5 os grupos apresentam aos outros grupos suas propostas de solução do desafio e discutem sobre as soluções encontradas;

- Na fase 6 todos os participantes que passam a formar um único grupo decidem em comum acordo como se dará a melhor solução do desafio e constroem um mapa conceitual único que indica a solução final;

- Na fase 7 o grupo avalia a proposição final com base na indagação: Esta solução realmente vai atender nossas expectativas em relação ao desafio proposto? Se a resposta for positiva inicia-se a próxima etapa (8) que é a idealização de um protótipo de serviços ou de produto para ser testado empiricamente. Se a resposta não for convincente para a maioria do grupo, então se reinicia o workshop a partir de uma proposta de desafio reformulada.

O modelo MASD pode ser reaplicado quantas vezes forem necessárias, alterando-se o desafio, o número de participantes, o local da aplicação, o insight inspirador inicial ou quaisquer outros elementos. No entanto, é fundamental que o processo se dê de modo colaborativo a partir de equipes multidisciplinares.

Visando a melhor compreensão da fundamentação teórica envolvida em cada fase do modelo MASD, a Figura 7 demonstra os conceitos utilizados e as respectivas siglas DT para Design Thinking e IA para Investigação Apreciativa. 


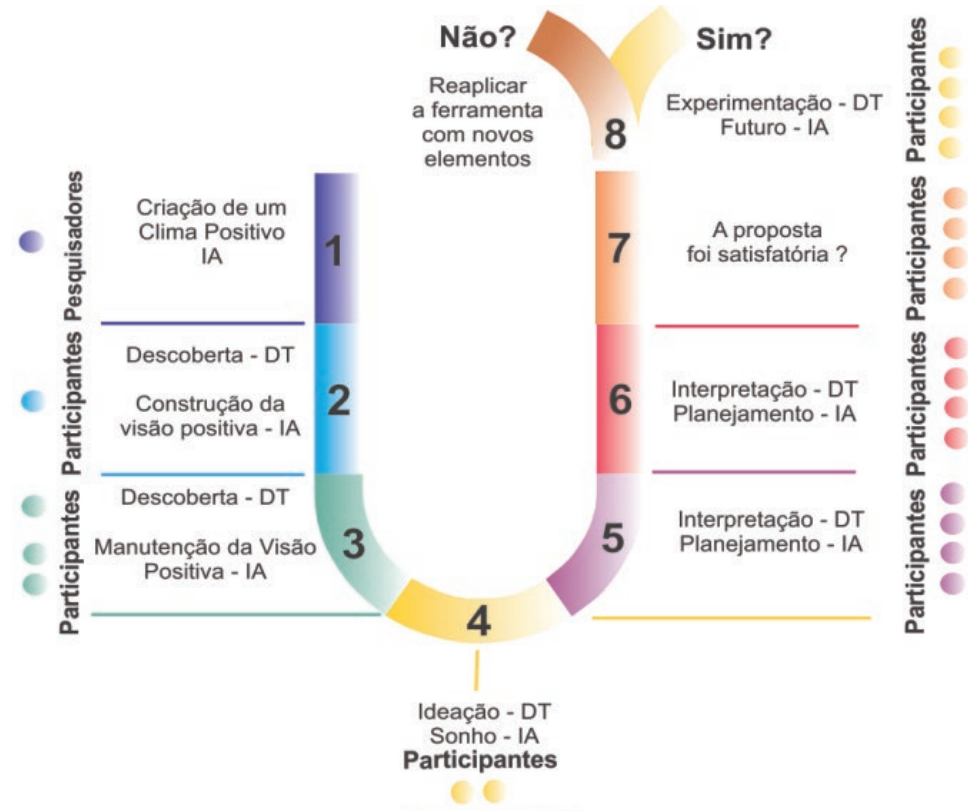

Figura 7: Conceitos do DT e da IA em cada fase do modelo de solução de desafios. Fonte: Os autores.

A validação interna do método apresentado se dá pelo embasamento teórico obtido pelo DT, pela IA e pela colaboração no ambiente macroergonômico. A validação externa, por sua vez, dá-se pelos resultados qualitativos demonstrados pelos participantes dos workshops e também pela possibilidade de se aplicar o modelo MASD para solucionar desafios de diversas naturezas.

\section{RESULTADOS}

Os resultados alcançados demonstram que o modelo atendeu plenamente aos objetivos propostos. Tais respostas podem ser analisadas pela descrição apresentada a seguir.

\subsection{Aplicação do modelo com os gestores da franqueadora}

O workshop cuja duração foi de 100 minutos foi aplicado a uma dupla de gestores da franqueadora. $O$ ambiente físico foi preparado em uma sala da empresa franqueadora. $O$ intuito da aplicação com apenas uma dupla de participantes ao invés de um grupo maior foi o de delimitar possíveis inadequações do modelo MASD e demarcar os ajustes necessários para as próximas aplicações.

O desafio proposto pelos gestores nesta experiência foi baseado na dificuldade que a franqueadora tem de manter uma comunicação eficiente com os franqueados. A franqueadora tem enviado informações importantes para os franqueados e a maioria deles não dá um feedback. Isso dificulta a gestão e a continuidade da comunicação.

Assim, o problema proposto foi: Como manter uma comunicação eficaz com os franqueados?

A finalidade desta aplicação foi alcançada a partir das sugestões de melhoria na fase da construção do diagrama de afinidades (fase 3 do modelo MASD). 


\subsection{Aplicação do modelo com outros gestores e profissionais da franquea- dora e de unidades de franquia}

A partir das sugestões propostas pelos gestores da franqueadora, o modelo MASD foi aperfeiçoado e o workshop foi aplicado neste segundo experimento com a participação de 4 stakeholders da rede de franquia, sendo: um gestor da área de $\mathrm{TI}$ da franqueadora; uma gerente de uma unidade própria de franquia (unidade pertencente à franqueadora); uma gerente de uma unidade de franquia; uma profissional da recepção de uma unidade de franquia. O tempo total da aplicação foi de 110 minutos.

O ambiente foi preparado com música instrumental alegre, oferta de doces, sucos e café em uma sala de reuniões da unidade de franquia. Embora esse ambiente fosse conhecido, o fato dos profissionais terem sido chamados para participarem de um projeto em um ambiente desconstruído de sua função rotineira fez a diferença. Os profissionais se sentiram entusiasmados, se envolveram com argumentações relevantes e se mostravam interessados em solucionar o desafio.

Segundo as premissas do DT, quanto mais diferentes forem os participantes de um workshop de cocriação, mais surpreendentes poderão ser os resultados alcançados (BROWN, 2010). Nesse sentido, o fato de a aplicação ter englobado também profissionais com pouca ou nenhuma função de gestão estratégica, e que atuam em funções distintas tanto na franqueadora quanto nas unidades de franquias, fez com que se cumprisse de modo empírico a premissa teórica proposta pelo DT. Da mesma forma, o método da IA prevê o envolvimento de todos os níveis de participantes em seus workshops.

O desafio proposto pelos gestores e profissionais foi: Como divulgar a franquia sem ter muitos recursos financeiros para investir?

Uma dupla apontou soluções (com riqueza de detalhes) mais voltadas à qualidade do atendimento. A outra dupla encontrou soluções estratégicas envolvendo toda a rede de franquias. A soma das soluções propostas pelas duplas tornou-se um plano de ação da franqueadora que foi validado posteriormente por um comitê e possivelmente foi colocado em prática.

\subsection{Aplicação do modelo com pesquisadores em uma conferência interna- cional de inovação}

O modelo aperfeiçoado foi aplicado num workshop de 200 minutos realizado pelos autores com 16 participantes pesquisadores da área do Design durante uma conferência internacional de inovação [Omitido para revisão cega]. O tempo maior de aplicação desse workshop deveu-se ao fato de que os participantes tiveram que construir um mockup físico (nesse caso, o mockup refere-se à construção de um objeto com materiais alternativos como papel, clips, cola, recortes de figuras, fitas barbantes, entre outros. Estes materiais foram ofertados pelos pesquisadores. Os grupos foram formados por doutores, doutorandos, mestres, mestrandos de vários estados brasileiros e um participante estrangeiro.

Visando inspirar a criatividade e a colaboração, o ambiente do workshop foi construído com boa iluminação da sala, incluindo a luz natural, um vídeo de inspiração criativa, a oferta abundante de doces, sucos, água e refrigerantes. Além disso, a liderança 
exercida pelos autores teve como princípio a criação de um ambiente descontraído.

A participação voluntária de pesquisadores da área do Design nessa conferência científica internacional demonstrou o interesse comum do grupo pelo tema inovação. Essa premissa sustentou a postura colaborativa desejável para esse tipo de experimento.

Como esse workshop tinha um caráter mais genérico, não direcionado a uma empresa ou projeto, os autores deste artigo decidiram propor o desafio inspirado numa situação cotidiana para criar um clima mais descontraído.

Assim, os participantes receberam como proposta o seguinte desafio: Como transformar uma "gambiarra" utilizada a partir de um "ato impensado" numa situação cotidiana em um produto ou serviço lúdico?

Entende-se por "gambiarra" uma solução alternativa que as pessoas criam para resolver um desafio cotidiano. Por exemplo: para pegar algum objeto num lugar alto, as crianças abrem uma gaveta e a utilizam como degrau. Esta "gambiarra" utilizada numa situação corriqueira pode se tornar um produto lúdico.

Os 4 grupos formados por 4 participantes entraram em consenso para propor a melhor solução de produto ou serviço utilizando o processo do modelo MASD. No final, foram apresentados 4 mockups representativos dos produtos lúdicos. Após o workshop os grupos se mantiveram conversando, discutindo sobre as soluções encontradas e se interessaram pelas teorias que formavam a estrutura do modelo MASD.

Nessa aplicação o intuito não foi o de se escolher uma única solução para se produzir um mockup, mas a produção de 4 mockups para se avaliar a riqueza de possibilidades que podem ser alcançadas por grupos colaborativos a partir de um desafio criativo.

\section{DISCUSSÃO}

As premissas do DT que envolvem o workshop de cocriação foram determinantes para a construção do modelo. Com base nesse instrumento foi possível propiciar uma convivência com ênfase nos aspectos criativo e colaborativo entre profissionais e pesquisadores que costumam se encontrar apenas para atender às demandas operacionais. Ao mesmo tempo, cumpre observar que o modelo foi concebido enfatizando os fatores humanos e ao mesmo tempo, atendendo a uma realidade contemporânea, onde profissionais de todas as áreas dispõem de pouco tempo para se encontrar descontraidamente no âmbito profissional ou de projeto. Neste sentido, cabe observar a relevância da investigação sob o viés da macroergonomia. Os participantes estavam habituados aos seus ambientes profissionais, seus escritórios, seus colegas, seus expertises técnicos. Quando saíram desta realidade foram influenciados por outros fatores, com pessoas que traziam outras experiências. Foram provocados a ser criativos e a visualizar uma solução para um desafio para somente depois concretizar o plano por meio de um mapa conceitual. Tudo ocorrendo num clima de descontração e tangibilizado por alimentos doces. Tais intervenções ocorreram a partir das variáveis ambientais, interpessoais e também tecnológicas que podem ser continuamente revisitadas para promover mudanças identificadas por gestores de organizações de todos os tipos.

De modo específico, no caso das franquias, o entendimento da variável interpes- 
soal do âmbito da macroergonomia se mostra mais desafiador, pois envolve o que deveriam ser redes de colaboração (gestores da franqueadora e das franquias, além dos fornecedores), mas que nem sempre funcionam e acabam resultando em conflitos. $O$ modelo MASD desenvolvido e aplicado de forma rotineira visa mitigar essa possibilidade.

Os resultados alcançados com a aplicação do modelo MASD com os gestores da franqueadora (fase de teste do modelo) se mostraram eficazes. No entanto, na percepção dos pesquisadores, o fato de tais gestores já serem parceiros profissionais fez com que a criatividade não aflorasse tanto quanto na aplicação realizada com outros grupos. Isso confirma as indicações do DT e da IA de que, quanto mais multidisciplinares forem as equipes dos workshops, mais eficazes serão os resultados.

No aspecto da macroergonomia este resultado embasado na variável interpessoal aponta para a necessidade de os gestores realizarem, também entre eles, atividades mais criativas envolvendo a participação de outros tipos de profissionais. Possivelmente os desafios enfrentados no nível estratégico também poderiam ser mitigados.

O resultado da aplicação do modelo MASD com os gestores e profissionais da franqueadora e franquias se apresentou de forma mais detalhada e criativa. Ambas as duplas compreenderam as tarefas de cada fase do workshop e se envolveram de modo dinâmico e criativo tanto na proposição de ideias quanto no encontro da solução final. Ao término do workshop as duplas chegaram a comentar que o aspecto colaborativo e, de certa forma, lúdico proporcionado pela atividade fez com que o grupo sugerisse espontaneamente novos workshops visando à solução de desafios futuros.

Analisando sob o viés da macroergonomia este resultado foi relevante e positivo. A variável ambiental foi a que causou o primeiro impacto positivo, pois uma sala de reuniões se transformou em um pequeno estúdio de criação. Ao mesmo tempo, a variável tecnológica foi evidenciada, pois os notebooks foram substituídos por materiais gráficos e desenhos colaborativos. O clima criado proporcionou uma interação pessoal produtiva capaz de indicar alinhamentos para trabalhos futuros.

Conforme descrito no item 4.3 a aplicação do modelo MASD junto a um grupo de pesquisadores num evento científico visou ao alcance de soluções criativas para desafios cotidianos. Os grupos formados em sua maioria por pessoas que não se conheciam criaram o cenário ideal para a aplicação do modelo MASD. Os resultados confirmaram os seguintes pressupostos previstos nos âmbitos do DT e da IA: quanto mais diferentes forem os participantes melhores os resultados; a solução é encontrada com mais facilidade quanto mais direcionado for o desafio; quando se estabelece um período de tempo para cada fase da ferramenta, o grupo se organiza melhor; quanto mais simples a linguagem utilizada, mais rápido é o entendimento; quando o usuário está envolvido no processo de solução do desafio, o resultado é mais adequado.

Neste caso, as variáveis propostas no âmbito da macroergonomia foram evidenciadas em todos os aspectos, pois os participantes não se conheciam entre si. Além disso, a mudança de ambiente e a precariedade de recursos tecnológicos de ponta fizeram com que a criatividade aflorasse. Entre os workshops apresentados neste artigo este foi o que mais apresentou descontração e criação colaborativa e lúdica ao mesmo tempo. Este resultado mostra também que longe da pressão dos desafios organizacionais rotineiros as pessoas são capazes de se envolver de modo mais completo com soluções inovadoras. 


\section{CONSIDERAÇÕES FINAIS}

A pesquisa relatada teve por objetivo convergir e aplicar elementos teóricos do DT e da IA na forma de um modelo de análise para solução de desafios em dois contextos: o primeiro num universo organizacional de franquias e o segundo no âmbito de pesquisadores. Foi demonstrado que, por meio do Modelo MASD embasado na capacidade humana de visualizar cenários positivos cuja aplicação se dá por um workshop colaborativo, os participantes conseguem analisar e solucionar desafios de modo satisfatório. As soluções foram alcançadas de modo simples e criativo.

Os resultados das aplicações apresentadas podem indicar solução alternativa para: o aumento do bem-estar no ambiente de trabalho, o incentivo à produtividade e à criatividade que leva à inovação no contexto da macroergonomia. Neste sentido podem ser exploradas as variáveis ambiental, tecnológica e interpessoal.

O modelo MASD aplicado no contexto de franquias auxiliou na simplificação da compreensão dos desafios, facilitou a visualização de processos, estimulou a colaboração e enfatizou resultados de uma equipe profissional em distintos níveis hierárquicos e de diferentes unidades de negócios.

No âmbito do grupo de pesquisadores foi possivel verificar que a sugestão da construção de um mockup referente a um suposto produto não intimidou o grupo; ao contrário, estimulou-o a incrementar a solução de modo entusiasmado.

Cabe salientar que os métodos originais da IA e do DT preveem meses de aplicação para surtirem efeitos perceptíveis. Contudo, por meio do processo simplificado do modelo MASD (Figuras 5 e 7), uma equipe colaborativa é capaz de encontrar uma solução consensual e viável num período de tempo máximo de 120 minutos, desde que o desafio seja direcionado para questões menos abrangentes. Se a equipe desejar ainda desenvolver um mockup (de acordo com os parâmetros descritos neste artigo), esse tempo pode chegar a, aproximadamente, 200 minutos como demonstrado na aplicação com a equipe de pesquisadores.

Tendo em vista que este experimento se ateve a dois universos, sendo um ligado a redes de franquias e outro voltado aos pesquisadores, recomenda-se também a investigação, com o mesmo tipo de abordagem, em outros tipos de empresas ou de grupos de pesquisa e de projeto.

Por fim, este artigo indicou possibilidades de alterações nas variáveis ambientais, tecnológicas e interpessoais presentes no âmbito macroergonômico. Tais alterações podem ser realizadas para o alcance de metas de curto prazo por meio da identificação de desafios bem definidos, com equipes colaborativas menores e multidisciplinares.

\section{AGRADECIMENTOS}

Agradecemos aos participantes dos workshops que envolveram os representantes da franquia Lady Lord e aos participantes da conferência Internacional IDEMI ocorrida na cidade de Florianópolis. Agradecemos também ao CNPq pelo apoio na forma de bolsa de estudos. 


\section{REFERÊNCIAS}

ABERGO - Associação Brasileira de Ergonomia - http://www.abergo.org.br. Acesso em 11/05/2018.

ADAMS, Robin S.; DALY, Shanna R.; MANN, Llewellyn M.; DALL'ALBA, Gloria. Being a professional: three lenses into design thinking, acting, and being. Design Studies, Elsevier, v. 32, n. 6, 2011.

AMBROSE, Gavin; HARRYS, Paul. Design Thinking: ação ou prática de pensar o Design. Porto Alegre: Bookman, 2011.

BEST, Kathryn. Fundamentos de gestão do Design. Porto Alegre: Bookman, 2012.

BOLAND JR., Richard; COLLOPY, Fred. Design matters for management. In: BOLAND JR., Richard; COLLOPY, Fred (Eds.). Managing as Designing. Stanford: Stanford University Press, 2004.

BOUJUT, Jean Francois; LAUREILLARD, Pascal. A co-operation framework for product-process integration in engineering design. Design Studies, Elsevier, v. 23, n. 5, Sept. 2002.

BRIAN, Leavy. Collaborative Innovation as the new imperative - design thinking, value, co-creation and power of pull. Strategy \& Leadership, v. 40, n. 2, 2012.

BROWN, Tim. Design Thinking: uma metodologia poderosa para decretar o fim das velhas ideias. Rio de Janeiro: Campus Elsevier, 2010.

CHERTO, Marcelo; CAMPORA, Fernando; GARCIA, Filomena, RIBEIRO, Adir; IMPERATORE, Luis Gustavo. Franchising: uma estratégia para a expansão de negócios. São Paulo: Premier Máxima, 2006.

CHIU, Mao Lin. An organizational view of design communication in design collaboration. Design Studies, Elsevier, v. 23, p. 187-210, 2002.

COOPERRIDER, David L.; SRIVASTVA, Suresh. Appreciative inquiry in organizational life. In: WOODMAN, Richard W.; PASMORE, William A. (Eds.). Research in organizational change and development. Greenwich, CT: JAI Press, 1987. v. 1. p. 129-169.

COOPERRIDER, David L.; SRIVASTVA, Suresh. Appreciative inquiry: rethinking human organization toward a positive theory of change. Academy of Management Review, v. 25, n. 4783-47894, Oct. 2000.

COOPERRIDER, David L.; WHITNEY, Diana; STAVROS, Jacqueline M. Manual da in- 
vestigação apreciativa. Rio de Janeiro: Qualimark, 2009.

CORREAA, Vanderlei Moraes; BOLETTI, Rosane Rosner. Ergonomia: fundamentos e aplicações. Porto Alegre: Bookman, 2015.

DUTRA, Myriam Cadorim. Comunicação e trabalho: as (im) possibilidades da investigação apreciativa. 229 f. Tese (Doutorado) - Faculdade de Comunicação Social -PUCRS, Porto Alegre, 2010.

ELLIS, Clarence A.; GIBBS, Simon J.; REIN, Gail. Groupware: some issues and experiences. Communications of the ACM, New York, v. 34, n. 1, p. 39-58, 1991.

FALZON, Pierre. Ergonomia. Blucher, São Paulo. 2007

FERREIRA, Aurélio Buarque de Holanda. Dicionário da Língua Portuguesa. Curitiba: Positivo, 2004.

FERRO, Gláucia de Salles. O Design como estratégia competitiva nas redes de franquias. Entrevista ao Site Design Brasil em 07/05/2013. Disponível em: <http://www. designbrasil.org.br/entre-aspas/o-design-como-estrategia-competitiva-nas-redes-de-franquias/\#.Vj_TPfmrTIU>. Acesso em: 08 nov. 2015.

FERRO, Gláucia de Salles. Modelo de análise para solução de desafios com base no Design Thinking e na investigação apreciativa: uma aplicação em uma rede de franquias. 128 f. Dissertação (Mestrado em Design) - PPG Design, UFPR, 2014.

FERRO, Gláucia de Salles; HEEMANN, Adriano. Vencendo desafios em franquias com Design Thinking e colaboração. In: GAMPI Plural, 4., 2014, Joinville, SC. Anais... Disponível em: <http://gampiplural.com.br/downloads/anais_2014.pdf>. Acesso em: 29 nov. 2015.

FRY, Ronald; BARRET, Frank; SEILING, Jane; WHITNEY, Diana. Appreciative inquiry and organizational transformation. Westport, Connecticut - London: Quorum Books, 2002.

HATCHUEL, Armand. Towards design theory and expandable rationality: the unfinished program of Herbert Simon. Journal of Management and Governance, v. 5, p. 3-4, 2002.

HEEMANN, Adriano; LIMA, Patrícia Jorge Vieira; CORREAA, Jeandrey Scuissiato. Fundamentos para o alcance da colaboração em Design. In: CONGRESSO BRASILEIRO DE PESQUISA E DESENVOLVIMENTO EM DESIGN, 8., 2008, São Paulo. Anais... São Paulo: Associação de Ensino e Pesquisa de Nível Superior de Design do Brasil (AEND), 2008. p. 1338-1349. 
HENDRICK, Hal W.; KLEINER, Brian M. Macroergonomia: uma introdução aos projetos de sistemas de trabalho. Rio de Janeiro: Virtual Científica, 2006.

HIGGINS, Julian P. T.; GREEN, Sally (Eds.). Cochrane Handbook for Systematic Reviews of Interventions Version 5.1.0. The Cochrane Collaboration, 2011.

IIDA, ITIRO. Ergonomia: projeto e produção. 2. ed. São Paulo: Edgard Blücher, 2005.

JOHANSSON-SKÖLDBERG, Ulla; WOODILLA, Jill; ÇETINKAYA, Mehves. Design Thinking: past, present and possible futures. Creativity and Innovation Management, v. 22, n. 2, 2013.

JOSHI, Ashwin W. Continuous supplier performance improvement: effects of collaborative communication and control. Journal of Marketing, v. 73, p. 133-150, 2009.

KELLEY, Tom E.; KELLEY, David. Confiança criativa: libere sua criatividade e implemente suas ideias. São Paulo: Ed. HSM, 2014.

KITCHENHAM, Barbara. Procedures for performing systematic reviews. joint Technical Report Software Engineering Group, Department of Computer Science, Keele University, National ICT Australia Ltd., Australia, 2004.

LOTAZZ, Claudio; CLEMÉNT, Denis; FALTINGS, Boi; SMITH, lan. Constraint based support for collaboration in design and construction. Journal of Computing in Civil Engineering, v. 13, n. 1, p. 23-35, 1999.

MAEMURA, Márcia Mitie Durante. Análise de conflitos e soluções adotadas por franquias do setor alimentício: um estudo multicaso. 232 f. Dissertação (Mestrado em Administração de Organizações) - Faculdade de Economia, Administração e Contabilidade de Ribeirão Preto, FEAPR-USP, Ribeirão Preto, São Paulo, 2009.

MARTIN, Roger. Design de negócios. São Paulo: Campus, 2010.

MARTINS, Rosane Fonseca de Freitas; MERINO, Eugênio Andrés Diaz. A gestão de Design como estratégia organizacional. Londrina: EDUEL, 2008.

MAURO, Paulo César. Guia do franqueador. São Paulo: Nobel, 2006.

MEDEIROS, E. Macroergonomia (Apostila do curso de especialização Superior em Ergonomia). Rio de Janeiro: CESERG, 2005.

MELO, Pedro Lucas de Resende; ANDREASSI, Tales. Franquias brasileiras. São Paulo: Cengage Learning, 2012. 
MOOHR, Jakki; SPEKMAN, Robert. Characteristics of partnership success: partnership attributes, communication behavior, and conflict resolution techniques. Strategic Management Journal, v. 15, p. 135-152, 1994.

MOZOTA, Brigite Borja de; KLÖPSCH, Cássia; COSTA, Felipe Costa Xavier da. Gestão do Design. Rio Grande do Sul: Bookman, 2010.

NATHAN, Greg. Profitable partnerships: improve your franchise relationships and change your life. USA: Franchise Relationships Institute, 2000.

PIMENTEL, Mariano; FUCKS, Hugo. Sistemas colaborativos. Rio de Janeiro: Campus, 2012.

PLÁ, Daniel. Tudo sobre Franchising. Rio de Janeiro: SENAC, 2001.

RIBEIRO, Adir; GALHARDO, Maurício; MARCHI, Leonardo; IMPERATORE, Luis Gustavo. Gestão estratégica do Franchising: como construir redes de franquias de sucesso. São Paulo: DVS, 2011.

SAMPAIO. C. Pereira; SOUZA. Juliana. A Macroergonomia na melhoria das condições de trabalho com ênfase nos aspectos de liderança: Estudo de caso com AMT em um restaurante. Revista Projética. Londrina, PR. 2012

SANDBERG, Jörgen. The constructions of social constructionism. Invisible Management, 1999.

SCARIOT, Cristiele; HEEMANN, Adriano; PADOVANI, Stephania. Understanding the collaborative-participatory design. Work, v. 41, p. 2701-2705, 2012.

SILVA, Isabel Cristina da; COSTA FILHO, Custódio Genésio da; BRITO, Mozar José de. Investigação apreciativa e pesquisa-ação: relação dialógica, complementaridade ou oposição? In: ENCONTRO DE ENSINO E PESQUISA EM ADMINISTRAÇÃO E CONTABILIDADE - EnEPQ, 4., 2013, Brasília, DF. Anais...

STEINBECK, Reinhold. Building creative competence in globally distributed courses through Design Thinking. Revista Comunicar, n. 37, v. XIX, p. 27-34, 2011.

STEMPFLE, Joachim; BADKE-SCHAUB, Petra. Thinking in design teams - an analysis of team communication. Design Studies, Elsevier, v. 23, n. 5, p. 473-496, 2002.

STRAUS, David. Criando colaboração produtiva: 5 formas de obter colaboração das equipes e aumentar resultados. Rio de Janeiro: Campus, 2003.

TAKAHASHI, Adriana Roseli Wünsch. Franchising: um sistema empreendedor de negócio: o caso da Apolar Imóveis. In: ANPAD, 2003, Atibaia, SP. Anais... 
THIVES JR., Juarez Jonas. Workflow: uma tecnologia para transformação do conhecimento nas organizações - estudo de caso no Conselho Estadual de Educação de Santa Catarina - CEEE/SC. 2. ed. rev. Florianópolis: Insular, 2001.

VAN DER HAAR, Dorieke; HOSKING, Dian Marie. Evaluating appreciative inquiry: a relational constructionist perspective. Human Relations, v. 57, n. 8, p. 1017-1036, 2004.

VARONA, Federico. La investigación Apreciativa: una manera nueva, provocadora y efectiva para construir las organizaciones del siglo XXI. Barranquilla, Colômbia: Ediciones Universidad Del Norte/UNINORTE, 2009.

VIANNA, Mauricio; VIANNA, Ysmar; ADLER, Isabel K.; LUCENA, Brenda; RUSSO, Beatriz. Design Thinking: inovação em negócios. Rio de Janeiro: MJV Press, 2012. 